\section{The Influence of Gardening Activities on Consumer Perceptions of Life Satisfaction}

\author{
T.M. Waliczek ${ }^{1}$ \\ Department of Agriculture, Texas State University, San Marcos, TX 78666
}

J.M. Zajicek ${ }^{2}$

Department of Horticultural Sciences, Texas A\&M University, College Station, TX 77843-2133

R.D. Lineberger ${ }^{3}$

Department of Horticultural Sciences, Texas A\&M University, College Station, TX 77843-2133

Additional index words. exercise, happiness, horticultural therapy, Life Satisfaction Inventory A, LSIA, Maslow's hierarchy of human needs, physical activity, quality of life

Abstract. A survey based on the Life Satisfaction Inventory A (LSIA) was used to investigate gardeners' and nongardeners' perceptions of life satisfaction. The LSIA was developed in 1961 by Neugarten and measures five components of quality of life including zest for life, resolution and fortitude, congruence between desired and achieved goals, high physical, psychological and social self-concept, and a happy optimistic mood tone. The survey was posted for four months on one of the largest online resources for Texas Master Gardeners within the Aggie Horticulture network, the Texas Master Gardener Web page (http: aggie-horticulture.tamu.edu/mastergd/mg.html). During the 4 months, 402 responses were gathered. Additionally, identical 'paper/pencil' format surveys were distributed to garden, church, social and community groups with about 400 responses received. In each group of participants, respondents differentiated themselves as gardeners or nongardeners by responding positively or negatively to the survey question, Do you garden? Results indicated statistically significant differences in comparisons of the overall life satisfaction scores with gardeners receiving higher mean scores indicating more positive results on the LSIA. When responses to individual statements were analyzed, results indicated statistically significant differences on $\mathbf{2 0 \%}$ of the statements. Differences were detected on statements relating to energy levels, optimism, zest for life, and physical self-concept with gardeners answering more positively on all statements when compared to nongardeners' responses. Additionally, gardeners rated their overall health and their physical activity levels higher than did nongardeners.

The Declaration of Independence indicates that Americans have always been concerned with the pursuit of happiness. Happiness, as a measurable variable, is considered to be one component of the overall idea of life satisfaction (McCall, 1975). Greater wealth is often thought to bring greater life satisfaction or more happiness (Diener et al., 1985). Average American incomes have risen since World War II, yet life satisfaction and happiness have remained steady (Myers, 2002). Although life satisfaction is an idea that most people find appealing, it appears that Americans are having a difficult time obtaining the goal since statistics indicate that about $25 \%$ of Americans suffer from mild depression at any given time (Seligman, 1994). Additionally, studies on life satisfaction have shown that the average American is 69\% happy, and only happy $54 \%$ of the time (Seligman, 2002).

Today, more Americans are living in fewer places. Populations within urban areas are growing, while the number of people residing

Received for publication 26 Oct. 2004. Accepted for publication 29 Jan. 2005.

${ }^{1}$ Associate professor.

${ }^{2}$ Professor.

${ }^{3}$ Professor. patients in hospitals have shown the exposure of these participants to views with windows overlooking natural areas resulted in positive well-being as expressed by less incidence of reported illness (Ulrich, 1984).

Research involving active participation with nature through gardening demonstrated that this activity provides psychological benefits such as increased self-esteem, reduced stress levels and increased social interaction among those involved (Cammack et al., 2002; Kaplan, 1973; Lewis, 1978; Patel, 1991; Waliczek etal., 1996), as well as economic benefits including reduced grocery bills, greater nutritional quality of food products and an improved sense of sufficiency (Hassan and Mattson, 1993; Patel, 1991). Research examining quality of life of community gardeners (Waliczek et al., 1996) concluded that community gardening influenced perceptions of quality of life, especially low-income minority gardeners in large city areas.

As urbanization of communities continues and our ever-increasing population resides in smaller places, research involving humans and their interaction with nature and green spaces is becoming increasingly crucial. The main objective of this study was to investigate the influence of gardening on perceptions of life satisfaction.

\section{Materials and Methods}

Instrumentation. Perceptions of life satisfaction of gardeners and nongardeners were measured using the Life Satisfaction Index (LSIA) (Neugarten etal., 1961). The original instrument was developed through an extensive 5-year study of a "relatively healthy, middle-class, urban Kansas City sample" (Adams, 1969). Initial data gathered information on respondents' life patterns, attitudes and values, activity levels, other members of the household, income and work, religion, organization involvement, social interaction, illness, loneliness, boredom, anger and self-image. From reported information, the final instrument was developed that measured psychological well-being and contained representational measures in distinguishable components including zest for life, resolution and fortitude, congruence between desired and achieved goals, physical, psychological and social self-concept, and optimism. A second study (Wood et al., 1969) conducted on a rural Kansas sample produced similar results to the original study (Adams, 1969) and added to the validity of the instrument.

Zest for life involves the level of enthusiasm a person has in various ideas or activities, regardless of the rewards involved for participation in the activity (Neugarten et al., 1961). Resolution and fortitude refers to extent to which a person takes personal responsibility for his/her life, whether or not the events in life were positive ornegative(Neugarten etal., 1961). Congruence between desired and achieved goals includes whether one feels that he/she has achieved the goals that he/she had set and viewed as important in accomplishing, or if one missed most of the life's opportunities (Neugarten et al., 1961). Physical, psychological and social self-concept refers to a person's concept of oneself in each of 


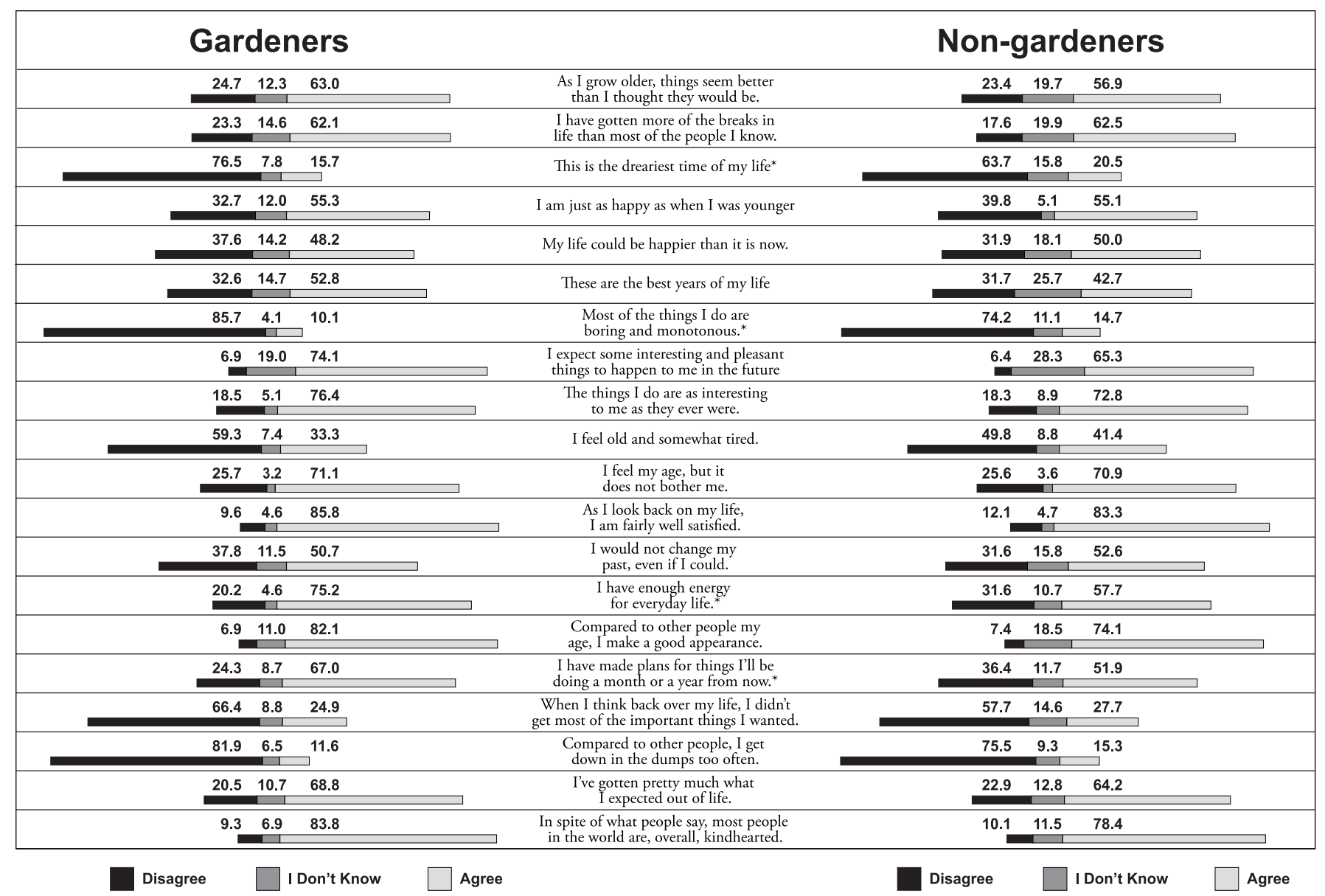

Fig. 1. Statements from the Life Satisfaction Index A (Neugarten et al., 1961) and the percentages of gardeners and nongardeners responding to statements as "Agree," "I don't know," and "Disagree" in the study evaluating the influence of gardening activities on consumer perceptions of life satisfaction. "Statistically significant at $p=0.05$.

these areas. Positive responses would indicate that a respondent is concerned with personal grooming and appearance, considers himself/ herself to have a valuable opinion and can give advice to others, feels that he/she is important to others and is proud of accomplishments he/she has had (Neugarten et al., 1961). Optimism is a measurement of whether a person expresses happy and optimistic attitudes and moods, or tends to have irritable and bitter attitudes and moods (Neugarten et al., 1961).

The Life Satisfaction Index instrument has been shown to be valid and reliable through its use in other research (Adams, 1969; Sexton and Munro, 1985; Sexton and Munro, 1988; Wood et al., 1969). The reported instrument reliability is 0.78 (Neugarten et al., 1961). Reliability is the extent to which the same test scores would be obtained if the test were administered again (Borg and Gall, 1989), and ranges from -1.0 to 1.0. The closer the reliability score is to 1.0 , the less error variance is present within the test and the more likely the differences observed during measurement by the test are those that are due to respondents' answers (Borg and Gall, 1989).

The Life Satisfaction Index consists of 20 statements. Participants were instructed to read each statement and rate the statement on a three point, Likert-type scale (Likert, 1967), which included the responses Agree, Disagree, and I don't know (Fig. 1). In addition to life satisfaction statements, respondents were asked two multiple-choice questions relating to daily physical activity levels and overall feelings of health. Demographic information was also gathered including age, gender, ethnicity, income and education level of the respondents.

Sample population. The sample was drawn from two sources. Approximately half of the sample population responded to the survey online where it was posted for 4 months, July through October, on one of the largest online resources for Texas Master Gardeners within the Aggie Horticulture network, the Texas Master Gardener Web page (http:aggie-horticulture. tamu.edu/mastergd/mg.html). The Master Gardener program is a national training and volunteer program that originated in the state of Washington in the 1970s. The program is run by the Agriculture Extension Agency. Volunteers for the program are trained in horticulture for 50 hours and commit to volunteer within the community for $50 \mathrm{~h}$ throughout the year following their training in order to become certified as a Master Gardener (Welsh, 2005).

Respondents self-selected themselves for inclusion in the study by visiting the webpage and choosing to answer the survey. The survey was not advertised in any other manner than the link to it on the webpage. The incentive for responding to the survey on the Internet was a packet of wildflower seed delivered to each participant in the mail. During the 4 months, 402 usable responses were gathered. Once participants entered answers, survey responses were automatically downloaded onto a computer spreadsheet. Survey respondents provided their names and addresses to have the wildflower seed mailed to them. This record of participants ensured that each respondent only provided one survey response.

Additionally, during the same four months of Internet survey collection, identical paper-pencil format surveys were distributed to garden, church, social and community service groups within Texas and parts of the Midwest. Groups were chosen for participation based on their ease of accessibility, interest level in participation and willingness to allow time for respondents to answer during meeting times. Four hundred usable surveys were received from this group. Each participant responding to the paper-pencil format survey was given a dollar as an incentive. In each group of participants, respondents differentiated themselves as gardeners or nongardeners by responding positively or negatively to the survey question, "Do you garden?"

Scoring and data analysis. The LSIA instrument for each respondent was scored using Microsoft Excel (Seattle, Wash.). Respondents received a score on the test instrument ranging 
Table 1. Analysis of variance comparisons of gardeners' and nongardeners' overall response scores ${ }^{\mathrm{z}}$ on the Life Satisfaction Index A (Neugarten et al., 1961 $)$ in the study evaluating the influence of gardening activities on consumer perceptions of life satisfaction.

\begin{tabular}{lcccccc}
\hline Category & $\mathrm{n}$ & Mean score $^{\mathrm{z}}$ & SD & $\mathrm{df}$ & $\mathrm{F}$ & $P$ \\
\hline Gardeners & 220 & 45.88 & 6.767 & 1 & 10.236 & $0.001^{*}$ \\
Nongardeners & 223 & 43.69 & 7.645 & & & \\
\hline
\end{tabular}

${ }^{2}$ Scores range from 20 to 60 . A score of 20 is the lowest possible score, and a 60 is the highest possible score based on a rating of $1=$ a negative response and a $3=$ a positive response to each of the 20 survey statements.

${ }^{y}$ Neugarten et al., 1961.

"Statistically significant at $p=0.001$.

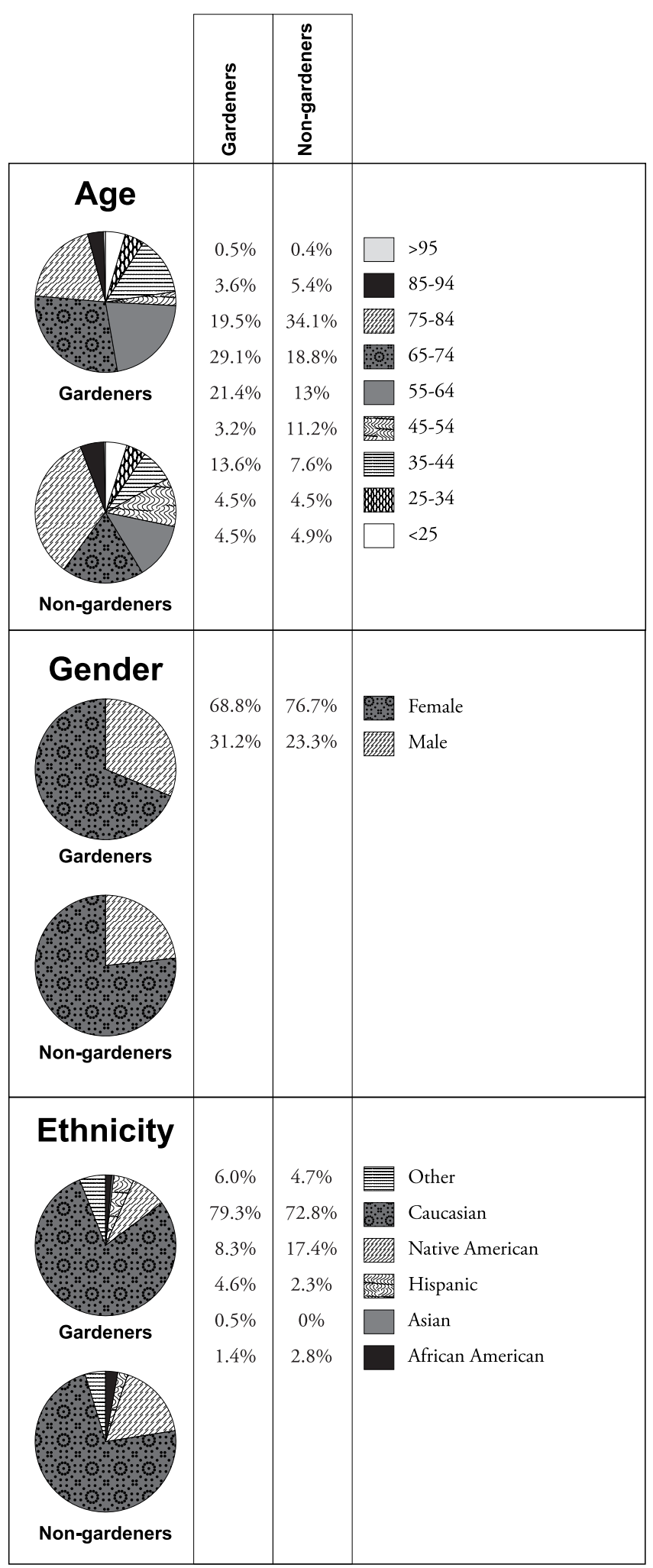

from 20 to 60 based on their answers. A positive answer to each survey statement resulted in a score of 3 and an overall score of 60 if positive answers were given for all 20 statements. A negative answer to each survey statement received a score of 1 and resulted in an overall score of 20 on the test if negative answers were given for all 20 statements. Answers of "I don't know" were considered neutral and, therefore, received two points each. Individual scores were then tabulated and entered into the overall data spreadsheet. Data collected was

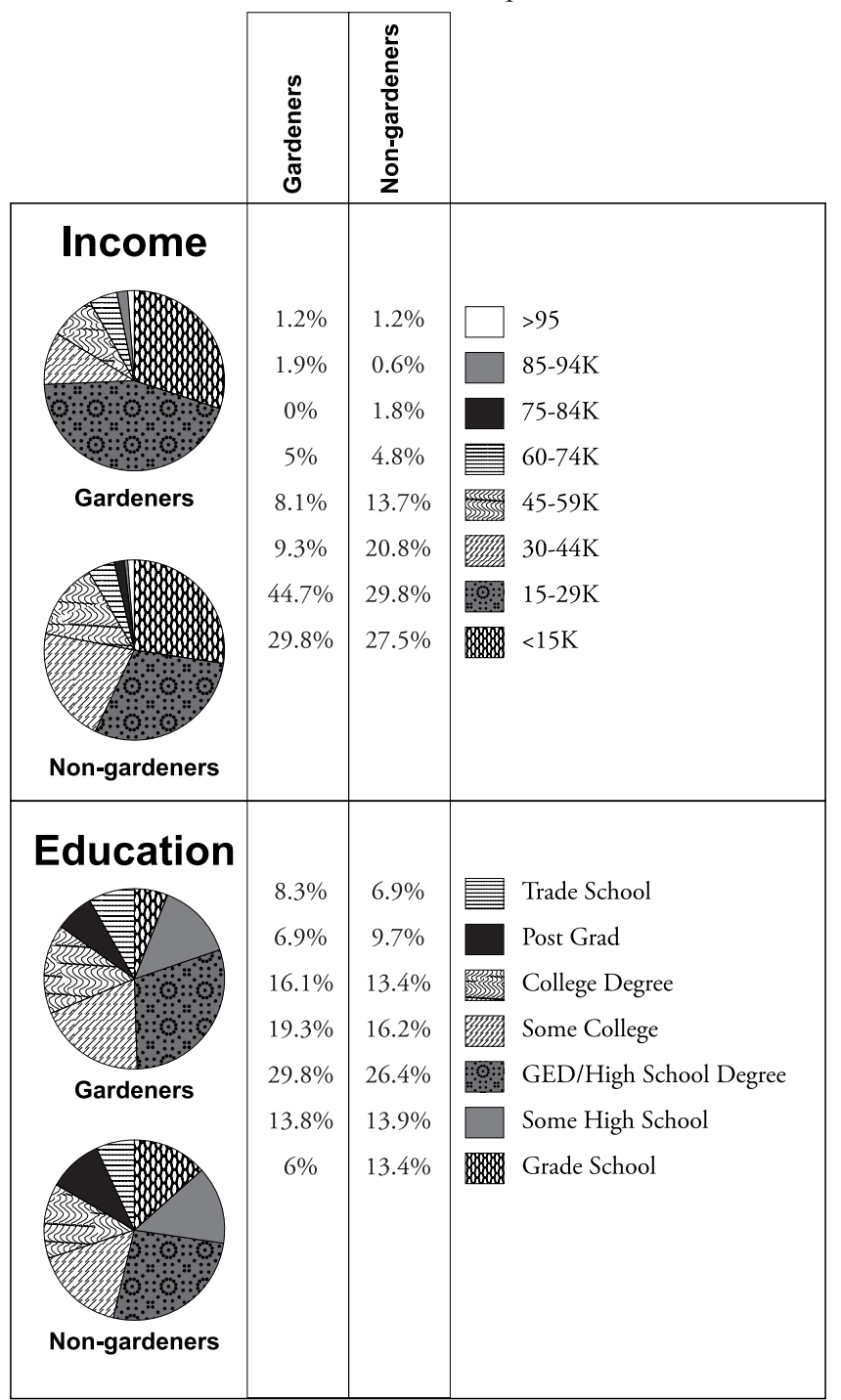

Fig. 2. Comparisons of gardeners' and nongardeners' demographic information on the variables of age, gender, ethnicity, income and education in the study evaluating the influence of gardening activities on consumer perceptions of life satisfaction. "Statistically significant at $p=0.05$. 
analyzed using the Statistical Package for the Social Sciences (SPSS) for Windows Release 11.5 (Chicago, Ill.). Statistical procedures included frequencies and multivariate ANOVA tests to determine differences between scores, individual statements and to determine any demographic influences.

\section{Results}

Because the samples were drawn from different sources, and had the potential to bias the data based on the respondent having access to a computer and an Internet connection, the samples were compared to see if they differed demographically. Statistically significant differences were found on variables including the income, age and education level of those responding on the Internet versus those responding on the traditional paper survey. The Internet group had obtained a higher level of education, was somewhat younger and had higher incomes. Because of the confounding differences within the sample, a subsample of 443 of the original 802 respondents was drawn to overcome any initial differences within the group. The subsample was drawn by sorting and matching the gardeners and nongardeners on the variables of income, age and education. To sort and match gardeners and nongardeners, data was initially analyzed to report and listmedian values for both gardeners and nongardeners for the variables of interest. From this information, researchers could observe where the data for each group overlapped, and select respondents within the suitable range of values for the variables of interest. Additionally, outlier data was removed from within the sample.

The overall sub-sample included comparatively even distributions of gardeners $(49.7 \%)$ to nongardeners $(50.3 \%$ ), with 220 total respondents being gardeners and 223 nongardener respondents. Demographic information for gardeners and nongardeners is presented in Fig. 2.

Gardeners vs. nongardeners. An analysis of variance compared gardeners' and nongardeners' responses. Results indicated statistically significant differences in comparisons of the overall scores of gardeners compared to nongardeners with gardeners receiving higher mean scores indicating more positive results on the LSIA $(P=0.001)$ (Table 1$)$. The mean score for gardeners on the LSIA was 45.88 while the mean score for nongardeners was 43.69. These differences indicated that gardeners appeared to have more positive perceptions of life satisfaction when compared to nongardeners.

Because overall scores indicated differences between gardeners and nongardeners, individual statements within the LSIA were analyzed to see if there were any trends as to which categories within the LSIA were different between the two groups. Statistically significant differences were found on $20 \%$ or 4 of the 20 life satisfaction inventory statements with each statement being answered more positively by those respondents who were reportedly gardeners (Fig. 1). Differences in statistically significant statements ranged in topic concepts and related to energy level, optimism, zest for life, and physical self-concept.
More than $75 \%$ of gardeners agreed with the statement "I have enough energy for everyday life" compared to only $57.7 \%$ of nongardeners. Differences were observed with $31.6 \%$ of nongardeners disagreeing to the statement compared to only $20 \%$ of gardeners $(P=0.001)$. Additional statistically significant differences between gardeners and nongardeners were noted in responses regarding how participants rated their overall health on a scale from poor to excellent $(P=0.015)$ (Fig. 3). More gardeners tended to rate their health as very good $(25 \%)$ or excellent $(15.7 \%)$ in comparison to nongardeners $(24.2 \%$ and $9.1 \%)$. Almost twice as many nongardeners rated their health as fair (19.2\%) when compared to gardeners responding the same way $(11.1 \%)$. Past research has found that nature can have a restorative effect on a fatigued mind(Kaplan and Kaplan, 1982). Some explanation for the restorative effect is due to the simpler stimuli involved in nature (Wilson, 1984). In addition, gardening has been thought to have physical benefits. Raking leaves for 30

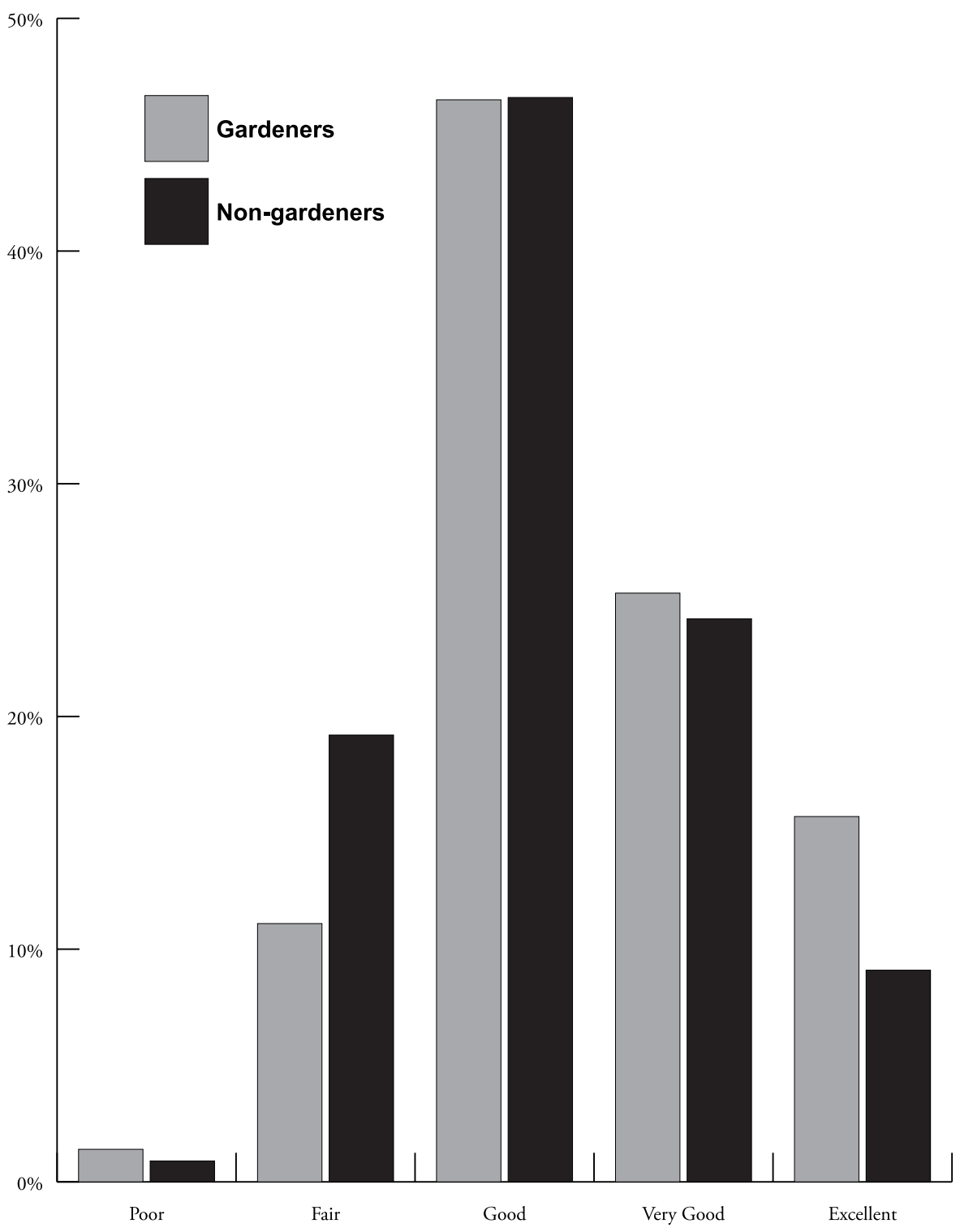

Fig. 3. Statistically significant comparisons ("statistically significant at $p=0.05$ ) of gardeners' and nongardeners' responses (poor, fair, good, very good, or excellent) to the statement, "Rate your overall health. "In the study evaluating the influence of gardening activities on consumer perceptions of life satisfaction. "Statistically significant at $p=0.05$. minhas comparablephysical benefits tojumping rope for 15 min (Nykamp, 1999; Taylor, 1990). Regular physical activity is known to increase energy levels, reduce the risks of developing disease and improve overall health (Fletcher et al., 1996).

Similarly, statistical significance was found when respondents rated their level of physical activity during the average day $(P=0.019)$ (Fig. 4). Nearly twice as many nongardeners considered themselves to be quite inactive $(13.4 \%)$ when compared to gardeners $(7.4 \%)$. In contrast, $25 \%$ of gardeners considered themselves to be very active compared to $18.5 \%$ of nongardeners. Similar percentages of gardeners and nongardeners considered themselves moderately active. Gardening has been classified as a moderate physical activity (Nykamp, 1999; Taylor, 1990). Gardening and personal home gardens have been linked in past research to the positive quality of life of elderly in independent living situations. The presence of home gardens were noted to provide exercise through outside 
garden work and increased consumption of home-produced foods leading to betternutrition and overall well-being (Schlettwein-Gsell etal., 1991). Gardening has also been seen as a way to increase physical activity in developmentally disabled populations. "Exercise tends to be more fun when it is purposeful, and having more fun results in more exercise" (Catlin, 1997).

Statistically significant differences were found concerning the zest for life statement, "This is the dreariest time of my life." The distribution of answers showed that gardeners were more positive in their responses with $76.5 \%$ of gardeners disagreeing with the statement compared to $63.7 \%$ of nongardeners. Nearly $21 \%$ of nongardeners agreed with the statement compared to only $15.7 \%$ of gardeners $(P=0.019)$. Gardeners also tended to disagree more often to the statement "Most of the things I do are boring and monotonous." Almost 86\% of gardeners disagreed with this statement compared to $74.2 \%$ of nongardeners disagreeing.

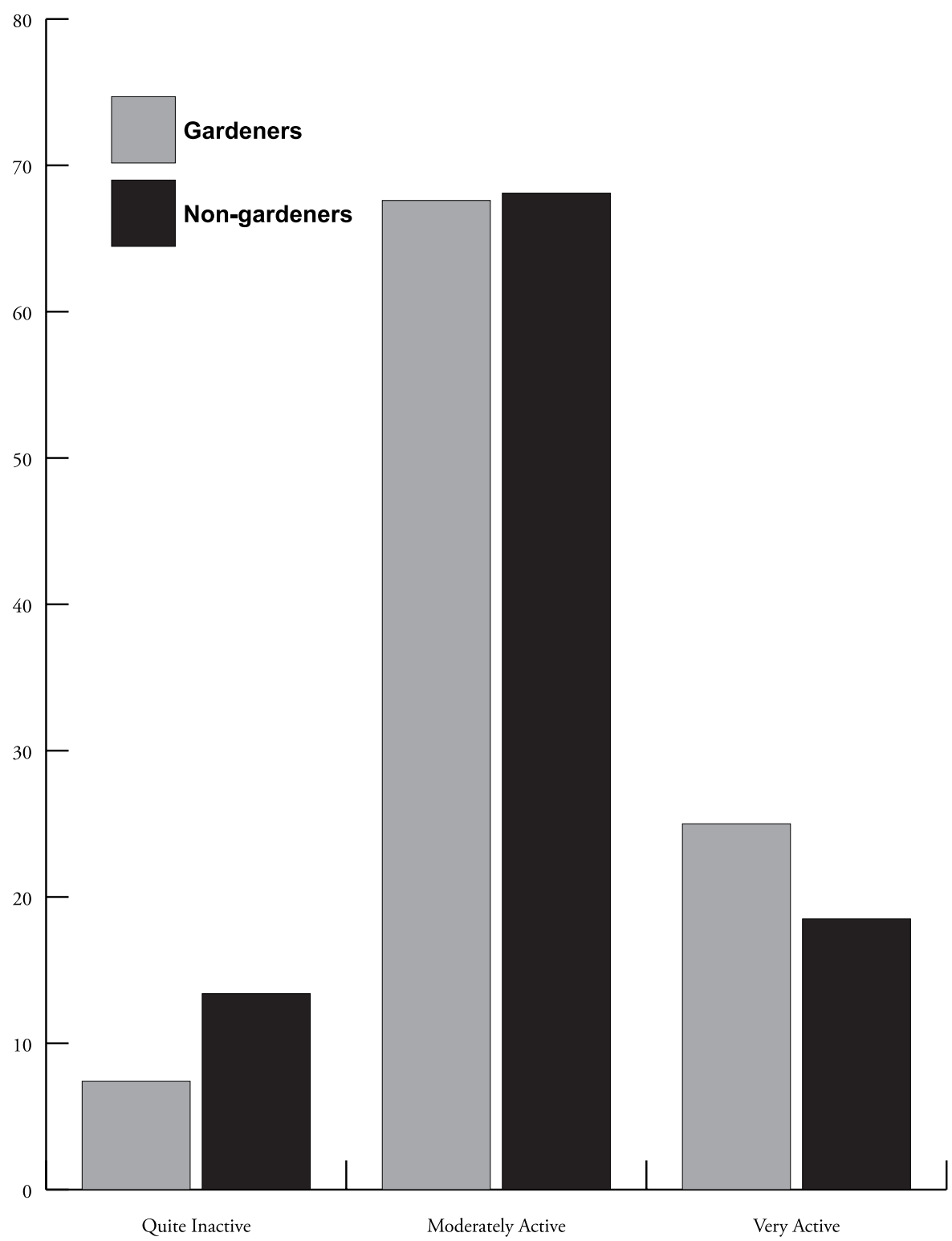

Fig. 4. Statistically significant comparisons ("statistically significant at $p=0.05)$ of gardeners' and nongardeners' responses (poor, fair, good, very good, or excellent) to a statement regarding physical activity in a usual day in the study evaluating the influence of gardening activities on consumer perceptions of life satisfaction.

In addition, more nongardeners agreed with the statement $(14.7 \%)$ compared to gardeners $(10.1 \%)(P=0.014)$.

Relating to optimism, more gardeners responded positively to the statement, "I have made plans for things I'll be doing a month or a year from now." Over $66 \%$ of gardeners agreed to the statement in comparison to the $51.9 \%$ of nongardeners agreeing $(P=0.002)$. Plants have been used to foster good mental health and for therapeutic treatment of mental illness since 1817 when Friends Hospital in Philadelphia began a gardening program for mentally disturbed people (Shapiro and Kaplan, 1997). In the field of Horticultural Therapy, the therapeutic use of plants for mental ailments has been said to promote positive results because of a variety of reasons including the patients feeling a sense of accomplishment, sustaining life in the plant and the patient gaining a sense of control over a small part of his/her life. In addition, plants are seen as a symbol of life and utilitarian. For many, natural areas are valued only for the resources they can provide economically and tangibly (Lewis, 1996). This view falls short of grasping the psychological forces that tie humans to nature (Wilson, 1984). This research supports the idea that contact with nature through hobbies such as gardening, and gardens as green spaces will not only support our physical being, but can have positive effects on one's mental well-being (Cammack et al., 2002; Kaplan, 1973; Lewis, 1978; Patel, 1991; Waliczek et al., 1996).

Life satisfaction can be considered by relating the concept to Maslow's hierarchy of humanneeds(Maslow, 1943). Maslow believed that humans progress from basic physiological needs, like food and safety, to the higher level needs, such as esteem and self-actualization (Maslow, 1943). Perhaps the convenience and expedience of living within an urban area caters to some of an individual's needs while leaving other needs unfulfilled. Gardens have been shown to help meet needs at each of these levels (Waliczek et al., 1996). This research supports the idea that gardening is a hobby that allows the participant to be outside appreciating nature, producing food and meeting physiological lower level needs on Maslow's pyramid of human needs, beautifying the community that meet midlevel esteem and societal needs, and allowing the gardener to create an expression of himself/herself to meet needs at the top of Maslow's pyramid, those of self-actualization. Perhaps, Americans are pursuing life satisfaction in the wrong places. When many Americans have some amount of free time, they spend it rushing to achieve the next task. More happiness or life satisfaction may come from slowing down and observing more.

\section{Literature Cited}

Adams, D.L. 1969. Analysis of a life satisfaction index. J. Gerontol. 24:470-474.

Appleton, J. 1986. The experience of landscape. John Wiley, New York.

Borg, W. and M. Gall. 1989. Educational research: An introduction, 5th ed. Longman Publ. New York. 
Cammack, C., T.M. Waliczek and J.M. Zajicek. 2002. The Green Brigade: The effects of a community-based horticultural program on the selfdevelopment characteristics of juvenile offenders. HortTechnology 12:82-86.

Catlin, P. 1997. Developmental disabilities and horticultural therapy practice, p. 131-156. In: S.P. Simson and M.C. Straus (eds.). Horticulture as therapy: Principles and practice. Food Products Press, New York.

Diener, E., J. Horowitz, and R.A. Emmons. 1985. Happiness of the very wealthy. Soc. Indicator Res. 16:263-274.

Fletcher, G.F., G. Balady, S.N. Blair, J. Blumenthal, C. Caspersen, B. Chaitman, S. Epstein, E.S. Sivarajan Froelicher, V.F. Froelicher, I.L. Pina, and M.L. Pollock. 1996. Statement on exercise: Benefits and recommendations for physical activity programs for all Americans. Amer. Heart Assn. 2 June 2004. http://www.cofc.edu/ crswebb/sessoms/Exstatement.htm.

Hassan, B.N. and R.H. Mattson. 1993. Family income and experience influence community garden success. J. Therapeutic Hort. 7:13-18.

Kaplan, R. 1973. Some psychological benefits of gardening. Environ. Behavior 5:145-162.

Kaplan, S and R. Kaplan. 1982. Cognition and Environment. Praeger, New York.

Lewis, C. 1978. Comment: Healing in the urban environment, Amer. Psychol. Assn. J. 7:330-338.

Lewis, C. 1996. Green nature/human nature. Univ. Ill. Press, Chicago.

Likert, R. 1967. The method of constructing an attitude scale, p. 90-95. In M. Fishbein (ed.). Readings in attitude theory and measurement. John Wiley, New York.

Maslow, A.H. 1943. A theory of human motivation. Psych. Rev. 50:370-396.

McCall, S. 1975. Quality of life. Social Indicators Res. 2:229-248.

Myers, D. 2002. The funds, friends, and faith of happy people. Amer. Psych. 35:56-67.

Neugarten, B.L., R.J. Havighurst, and S.S. Tobin. 1961. The measurement of life satisfaction. J. Gerontol. 16:134-143.

Nykamp, J. 1999. Gardening improves physical health, well-being. Holland Sentinel. 1 Jan. 1999. http://www.thehollandsentinel.net/stories/01/01/99/fea_gardening.html.

Orians, G. and J. Heerwagen. 1992. Evolved responses to landscapes, p. 557. In: J.H. Barkow, L. Cosmides, and J. Tooby (eds.). The adapted mind: Evolutionary psychology and generation of culture. Oxford Univ. Press, New York.

Patel, I.C. 1991. Gardening's socioeconomic impacts: Community gardening in an urban setting. J. Ext. 29:7-8.

Relf, P.D. 1997. People-plant relationship, p. 21-42. In: S.P. Simson and M.C. Straus (eds.), Horticulture as therapy: Principles and practice. Food Products Press, New York.

Seligman, M.E.P. 1994. What you can change and what you can't. Alfred A. Knopf, New York.

Seligman, M.E.P. 2002. Authentic happiness. Free Press, New York.

Sexton, D.L. and B.H. Munro. 1985. Impact of a husband's chronic illness (COPD) on the spouse's life. Res. Nurs. Health 8:83-90.

Sexton, D.L. and B.H. Munro. 1988. Living with a chronic illness: The experience of women with chronic obstructive pulmonary disease (COPD). W.J. Nurs. Res. 10:26-44.

Schlettwein-Gsell, D., D. Barclay, M. Osler, and A. Trichopoulou. 1991. Euronut SENECA study on nutrition and the elderly. Dietary habits and attitudes. Eur. J. Clin. Nutr. 45(3):83-96.

Shapiro, B.A. and M.J. Kaplan. 1997. Mental illness and horticultural therapy practice, p. 157-197. In: S.P. Simson and M.C. Straus (eds.), Horticulture as therapy: Principles and practice. Food Products Press, New York.

Taylor, M.K. 1990. The healthy gardener. Flower and Garden (March/April):46-47.

Ulrich, R.S. 1984. View through a window may influence recovery from surgery. Science 224:420-421.

U.S. Department of Agriculture. 1993. An introductory guide to urban and community forestry programs. For. Serv. S. Reg. (Atlanta) For. Rpt. R8-FR 16.

Waliczek, T.M., R.H. Mattson, and J.M. Zajicek. 1996. Psychological benefits of community gardening, J. Environ. Hort. 14:204-209.

Welsh, D. 2005. Texas Master Gardener webpage. History of the Texas Master Gardener program, 23 Jan. 2005. http://aggiehorticulture.tamu. edu/mastergd/tmghistory.html.

Wilson, E.O. 1984. Biophilia. Harvard Univ. Press, Cambridge.

Wood, V., M.L. Wylie, and B. Sheafor. 1969. An analysis of a short self-report measure of life satisfaction: Correlation with rater judgments. J. Gerontol. 24:465-469. 